\title{
After Action Report: Specific Manufacturing Capability \\ 2014 Evaluated Drill October 29, 2014
}

December 2014

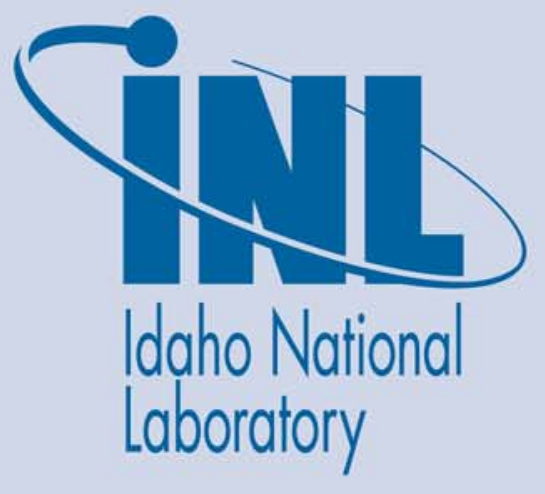

The INL is a U.S. Department of Energy National Laboratory operated by Battelle Energy Alliance 


\section{DISCLAIMER}

This information was prepared as an account of work sponsored by an agency of the U.S. Government. Neither the U.S. Government nor any agency thereof, nor any of their employees, makes any warranty, expressed or implied, or assumes any legal liability or responsibility for the accuracy, completeness, or usefulness, of any information, apparatus, product, or process disclosed, or represents that its use would not infringe privately owned rights. References herein to any specific commercial product, process, or service by trade name, trade mark, manufacturer, or otherwise, does not necessarily constitute or imply its endorsement, recommendation, or favoring by the U.S. Government or any agency thereof. The views and opinions of authors expressed herein do not necessarily state or reflect those of the U.S. Government or any agency thereof. 


\title{
After Action Report: Specific Manufacturing Capability 2014 Evaluated Drill October 29, 2014
}

December 2014

Idaho National Laboratory Idaho Falls, Idaho 83415

\author{
http:/linl.gov
}

Prepared for the U.S. Department of Energy Under DOE Idaho Operations Office

Contract DE-AC07-05ID14517 
This page intentionally left blank. 
Emergency Management

\section{After Action Report: Specific Manufacturing Capability 2014 Evaluated Drill October 29, 2014}

INL/EXT-14-33739

Revision 0

November 2014
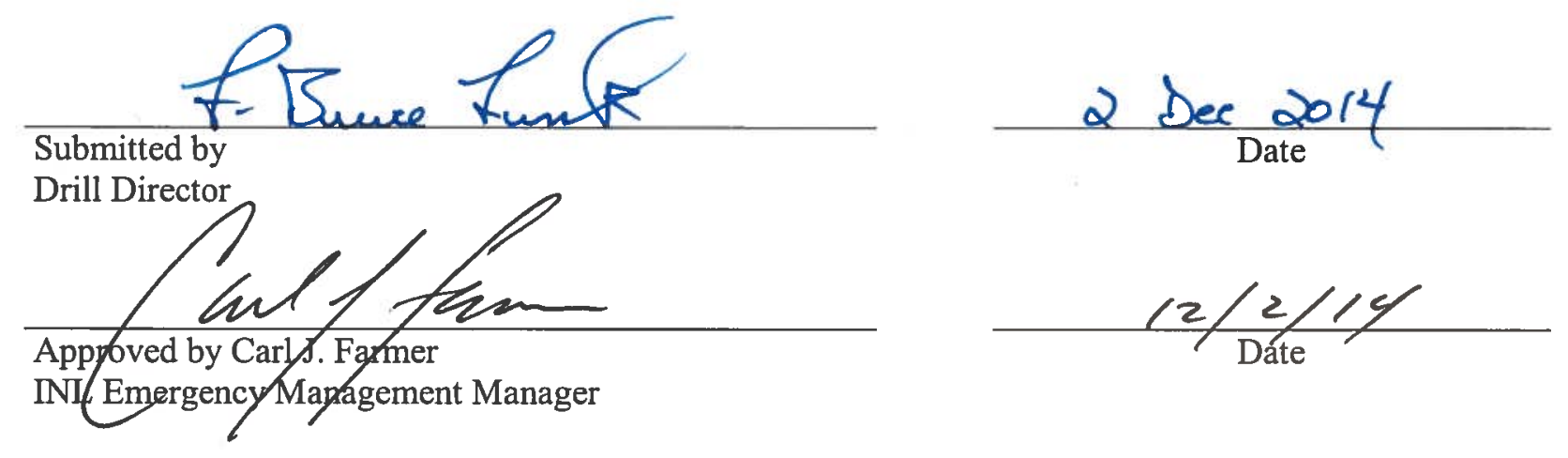
This page intentionally left blank. 


\section{CONTENTS}

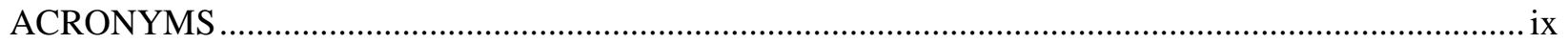

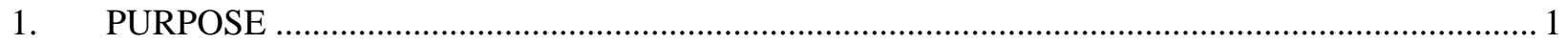

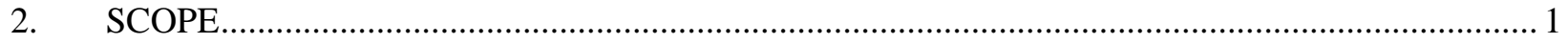

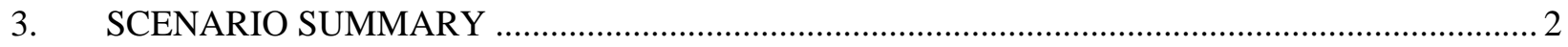

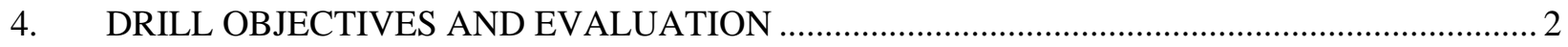

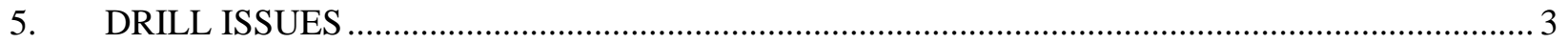

5.1 Emergency Response Organization Response ................................................................ 3

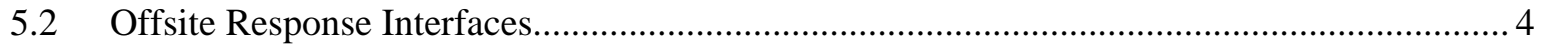

5.3 Emergency Event Categorization and Classification ...................................................... 4

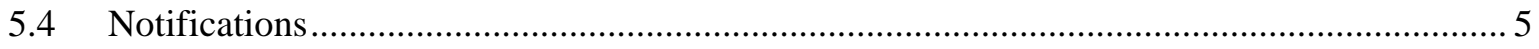

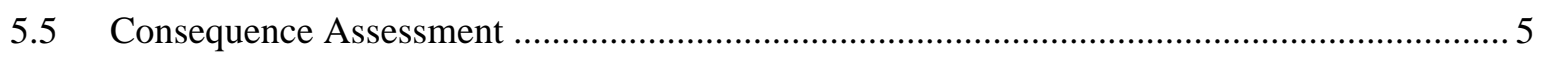

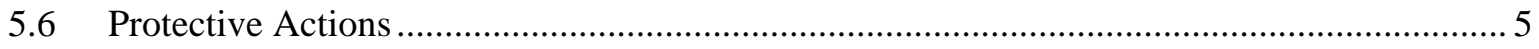

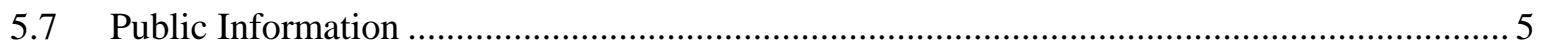

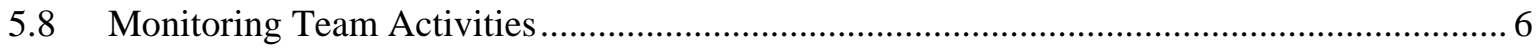

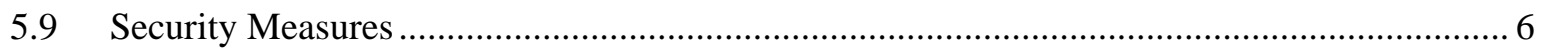

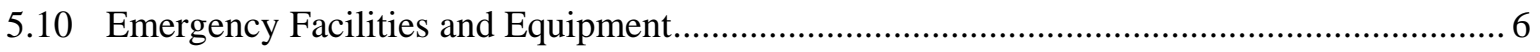

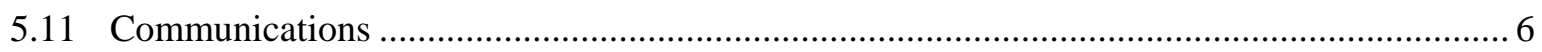

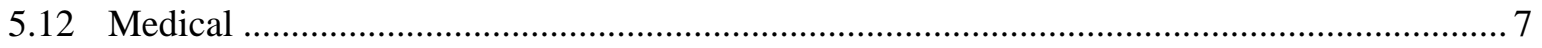

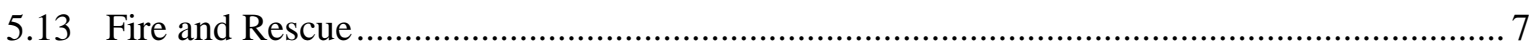

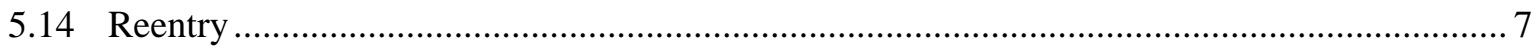

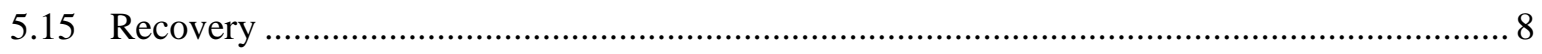

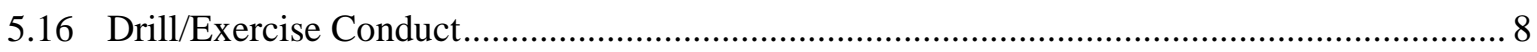

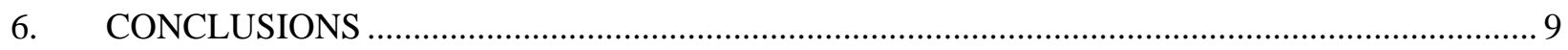

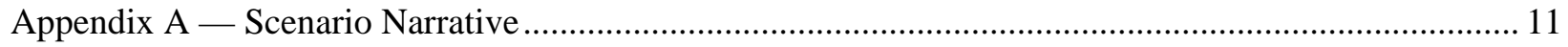

TABLES

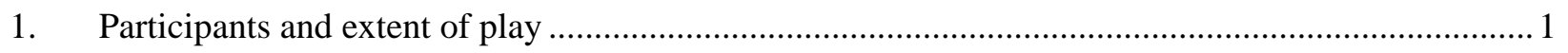

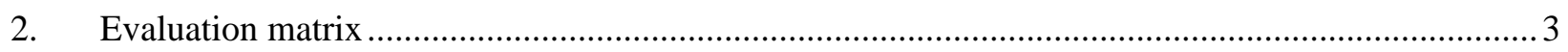


This page intentionally left blank. 


\section{ACRONYMS}

CFA Central Facilities Area

EAM emergency action manager

ECC emergency control center

ED emergency director

EOC emergency operations center

ERO emergency response organization

FD Fire Department

IC Incident Commander

INL Idaho National Laboratory

OE operational emergency

PA protective action

PAL Personnel Accountability Leader

SMC Specific Manufacturing Capability

TAN Test Area North

WCC Warning Communications Center 
This page intentionally left blank. 


\section{After Action Report: Specific Manufacturing Capability 2014 Evaluated Drill October 29, 2014}

1. PURPOSE

On October 29, 2014, the Specific Manufacturing Capability (SMC), operated by Battelle Energy Alliance LLC at Idaho National Laboratory (INL), conducted an evaluated emergency drill to allow the SMC Emergency Response Organization (ERO) to demonstrate its ability to respond to and mitigate an emergency event.

\section{SCOPE}

Participants and their extent of play are shown in Table 1.

Table 1. Participants and extent of play.

\begin{tabular}{|c|c|}
\hline Participants & Extent of Play \\
\hline \multicolumn{2}{|c|}{ INL Organizations } \\
\hline Bus Operations & Simulated \\
\hline $\begin{array}{l}\text { Central Facilities Area (CFA) Emergency Control } \\
\text { Center (ECC) }\end{array}$ & Limited participation: control cell \\
\hline INL Emergency Operations Center (EOC) & Limited participation: control cell \\
\hline INL Fire Alarm Center & Limited participation: notifications only \\
\hline INL Fire Department (FD) & Full participation \\
\hline INL Warning Communications Center (WCC) & Full participation \\
\hline Security & Limited participation: notifications only \\
\hline
\end{tabular}




\section{SCENARIO SUMMARY}

\section{Background}

SMC is located on the INL Site and develops specific manufacturing capabilities as directed by the Department of Defense and manufactures armor for the U.S. Army. SMC is classified as a Department of Energy Hazard-Category-3 nuclear facility. SMC consists of fabrication and assembly, rolling operations, and support facilities and provides product and recyclable material transportation. Fabrication and assembly facilities contain production areas and space for offices, support functions, and service areas. Test Area North (TAN)-679, TAN-679A, and TAN-681 operations include areas for process production; shipping, receiving, and storing material; a Radiological Control field office; a maintenance area; a boiler room; administrative offices; and change room facilities. SMC support facilities include a guard post (TAN-676), a cafeteria and an Emergency Control Center (ECC) (TAN-678), utilities, offices, a warehouse, and an office complex. Access to SMC is obtained through the TAN-676 guardhouse.

\section{$\underline{\text { Drill Start }}$}

It was a normal working day at SMC.

A diesel fuel tanker was inside the facility preparing to back up to underground tank accesses. As the driver was positioning his truck, he had a heart attack. His foot pushed down on the accelerator, and he drove full speed into the main transformer light pole northeast of TAN-681. The force of the truck broke the pole in half, and it fell on to the top of the tanker truck and punctured its main tank. Diesel fuel poured out onto the ground and flowed toward TAN-681 and westward toward the facility fence. The powered transformer and broken power lines ignited some diesel on the surface of the tanker. The driver (represented by a manikin) was slumped over the steering wheel.

The INL Fire Department (FD) was dispatched to the scene. The SMC emergency action manager (EAM) categorized the event as an operational emergency (OE), Non-radiological Release SMC-ALL-4.OE.1. An initial protective action (PA) of sheltering for the facility was ordered by the EAM (simulated) and was upgraded to a full facility evacuation (simulated) later. Appropriate notification forms were completed and faxed to the Warning Communications Center (WCC). Offsite notifications were simulated as being completed.

Electrical power was simulated as having been shut off to the power pole (causing simulated back-up generators to power up in the facility). The EAM ensured that a consequence assessment form was faxed to the emergency operations center (EOC) concerning the burning and leaking diesel fuel. A recovery manager was appointed, and the drill was terminated.

\section{DRILL OBJECTIVES AND EVALUATION}

NOTE: Only the SMC ERO was formally evaluated during the drill. All other player organizations were conducting a training evolution.

During the drill, 12 of the 16 standardized INL objectives were evaluated for SMC using the appropriate demonstration criteria. Eight objectives were rated satisfactory, and four were rated satisfactory with improvement needed. 
The ratings in Table 2 are based on the issues that follow in Section 5 of this report.

Table 2. Evaluation matrix.

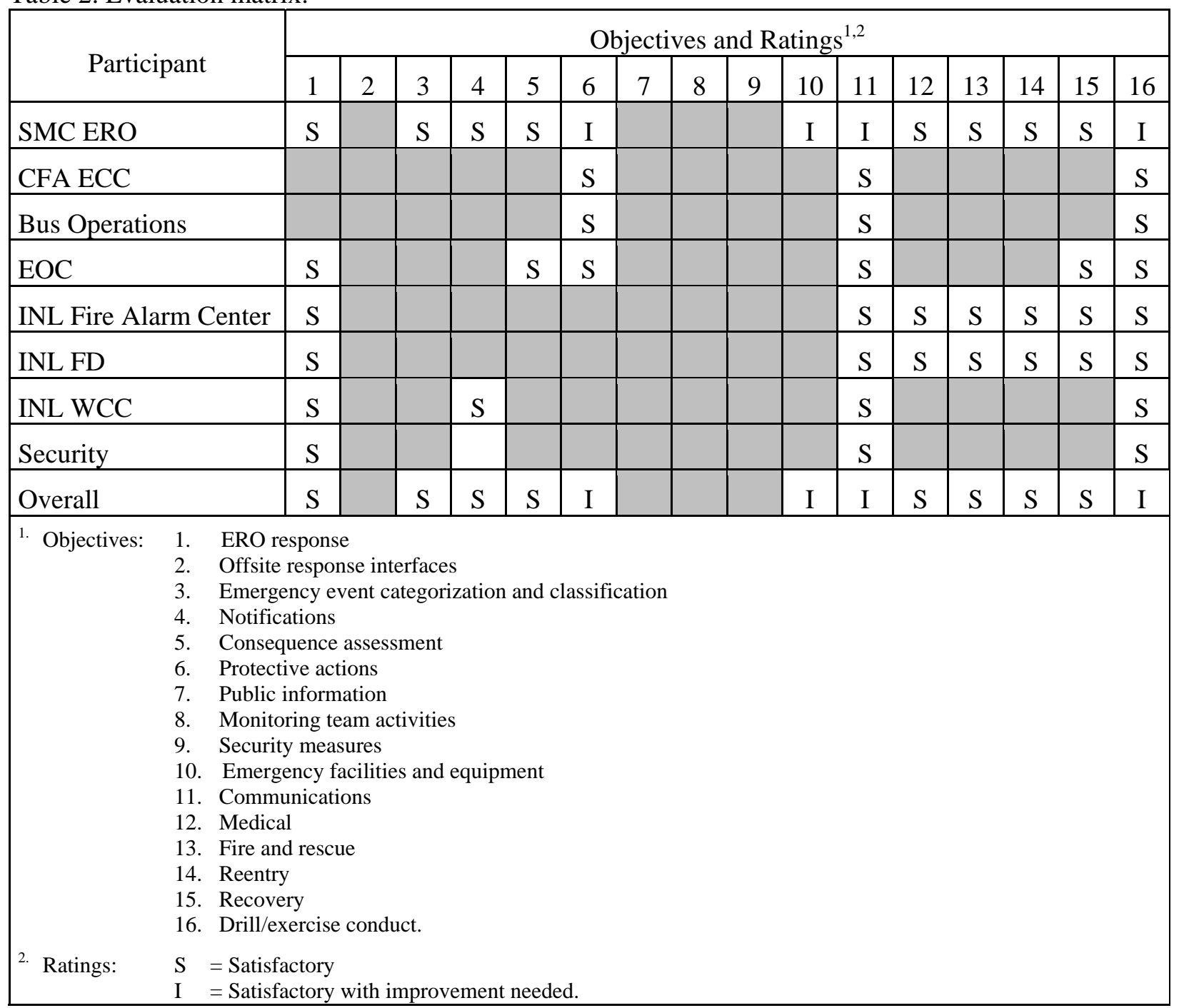

\section{DRILL ISSUES}

The following issues are specific to the evaluation of the SMC ERO. Each item has been evaluated and entered into the appropriate issues management system.

\subsection{Emergency Response Organization Response}

Given the facility procedures/plan, the ERO will respond to, monitor, and evaluate the specific indicators of an emergency for mitigation of the consequences and bring the emergency situation under control. 


\section{$\underline{\text { Discussion }}$}

The EAM quickly took control of his responsibilities. On the way to the ECC, the EAM called the Fire Alarm Center to request FD Station 3 response and made a voice announcement for all employees to stay clear of the TAN-679/TAN-675 area. He established firm command and control in the ECC and ensured he had communications with the Incident Commander (IC) through a radio relay person (the EAM was on the radio with the IC until the ECC on-scene communicator arrived in the ECC). This drill marked the second time in a row when the Shift Supervisor acted as the incident scene communicator, and it worked well.

At $\mathrm{T}+11$, the EAM used the voice announcement system to direct the on-duty ERO team to respond to the ECC and asked for the Shift Supervisor to call him in the ECC. He used the system at T + 12 to call for an assistant EAM to report to the ECC. At T + 14, the EAM simulated a voice announcement for all personnel to take shelter. At T +17 , the EAM had the WCC called to activate the other on-duty ERO teams.

The ERO team responded well and in a timely manner to the ECC. All team members were aware of and confident in their duties and facilitated timely decision-making by the EAM. The ECC was declared operational at $\mathrm{T}+22$.

The EAM ordered evacuation of all buildings (simulated) at $\mathrm{T}+37$ and had the planning communicator simulate making a request to the Central Facilities Area (CFA) ECC for buses. Injured personnel (simulated) were tracked well, and their appropriate information was relayed via WebEOC and the follow-up notification form.

The EAM ensured tight communications with the EOC via regular command bridge calls with the emergency director (ED).

$\underline{\text { Issues }}$

- $\quad$ None.

\subsection{Offsite Response Interfaces}

Given the facility procedures/plan, the ERO will coordinate and interface with response organizations to protect the environment and the health and safety of the public.

\section{$\underline{\text { Discussion }}$}

- Not evaluated in this drill.

\subsection{Emergency Event Categorization and Classification} OE.

Given the facility procedures/plan, the ERO will accurately and promptly categorize and classify the

\section{Discussion}

The EAM categorized the event with SMC-ALL-4.OE.1 (Nonradiological release) at $\mathrm{T}+33$, which was within the required 15 minutes of event determination.

$\underline{\text { Issues }}$

- None. 


\subsection{Notifications}

Given the facility procedures/plan, the ERO will report emergencies and conduct follow-up notifications to the appropriate organizations within the required time.

\section{Discussion}

Initial notifications were complete by $\mathrm{T}+43$, well within the 30 minute timeline allowed for this event. A follow-up notification form, including patient information and reclassifying the event to SMC-ALL-1.OE.1 (Fire), was sent at $\mathrm{T}+63$, and notifications were complete at $\mathrm{T}+70$.

The notifications specialist performed extra duty very well by assisting the EAM with accuracy of information and in assisting the information management coordinator with WebEOC entries.

$\underline{\text { Issues }}$

- None.

\subsection{Consequence Assessment}

Given the facility procedures/plan, the ERO will assess actual and potential onsite and offsite consequences of an emergency.

\section{$\underline{\text { Discussion }}$}

The consequence assessment form was sent in at $\mathrm{T}+81$.

\section{Issues}

- None.

\subsection{Protective Actions}

Given the facility procedures/plan, the ERO will respond to emergency conditions to protect onsite personnel and the public by implementing specific, predetermined actions.

\section{Discussion}

The EAM ordered sheltering for the facility initially and then changed to facility-wide evacuation later on. He requested three buses from CFA bus operations to support that action.

Despite accountability not being required because of the initial sheltering decision, the drill director asked the personnel accountability leader (PAL) to exercise the process of establishing where all the employees were in the buildings. The Argus terminal in the ECC was out of order, which caused the PAL to go to the guardhouse to obtain the individual building printouts, thus delaying the accountability report. Accountability (knowing location of each employee) was achieved at $\mathrm{T}+48$-within the standard of 30 minutes and not exceeding 45 minutes.

\section{Opportunity for Improvement}

- The SMC emergency planner should work with SMC security personnel and Argus administrators to find a solution to the non-working terminal. SMC LabWay No. SMC-CO 2014-1288 assigned.

\subsection{Public Information}

Given the facility procedures/plan, the ERO will demonstrate an emergency public information program.

\section{Discussion}

- $\quad$ Not evaluated in this drill. 


\subsection{Monitoring Team Activities}

Given the facility procedures/plan, the ERO will provide facility/site monitoring teams in support of consequence assessment activities.

\section{Discussion}

- Not evaluated in this drill.

\subsection{Security Measures}

Given the facility procedures/plan, security will respond to, monitor, and evaluate the specific indicators of an emergency for mitigation of the consequences and bring the emergency situation under control.

\section{$\underline{\text { Discussion }}$}

- Not evaluated in this drill.

\subsection{Emergency Facilities and Equipment}

Demonstrate the adequacy of facilities, equipment, displays, and other materials to support emergency operations.

\section{Discussion}

The SMC ECC has two display projectors. At the start of the drill, one was found to be inoperable. However, the ERO team was able to work around this issue during the drill. The fax machine functioned properly.

\section{Opportunity for Improvement}

- This is the second time that a projector in the westernmost position has malfunctioned for apparent heat-related reasons. Its position nearest the ceiling air vent may be a contributing factor. SMC emergency planners should work with facility maintenance and/or an audio-visual repair specialist to determine the cause of the malfunctions. SMC LabWay No. SMC-CO 2014-1289 assigned.

\subsection{Communications}

Communications capabilities are managed in support of emergency operations to ensure prompt and appropriate flow of accurate information during an emergency.

\section{Discussion}

WebEOC significant event entries were posted out of order, and at one point the EOC reminded the SMC ECC to post its entries that had not yet been reviewed. However, the entries were made regularly.

The EAM ensured a radio and operator were present at the incident scene. However, communications into the ECC were not clear or loud enough.

A controller monitoring communications between the ECC and the incident scene logged four different occasions when a pair of data were voiced in a transmission but only one of them was repeated back as having been heard. 


\section{Opportunities for Improvement}

- Regular checks of the WebEOC entries should be made by the information management coordinator to ensure that the entries are reviewed/posted and appear on the significant events display. SMC LabWay No. SMC-CO 2014-1290 assigned.

- The SMC emergency planner should conduct some radio tests for clarity between the SMC facility and the ECC radio. Use one of the qualified ECC radio communicators to help with this research. SMC LabWay No. SMC-CO 2014- 1291 assigned.

- Send this report, or a summary of it, to the ERO teams emphasizing the need to pass one critical piece of information at a time to minimize the chance of information being lost. SMC LabWay No. SMC-CO 2014-1292 assigned.

\subsection{Medical}

Given the facility procedures/plan, medical response personnel will respond to, monitor, and evaluate the specific indicators of an emergency for mitigation of the consequences and bring the emergency situation under control.

\section{Discussion}

Station 3 medical personnel worked very well with the controller in simulating use of a manikin for the truck driver and his associated vitals information. The IC prevented work on the victim until power had been isolated to the power pole and the scene was safe. The ambulance personnel were satisfied with their experience with the controller-supplied information.

\section{Issues}

- None.

\subsection{Fire and Rescue}

Given the procedures/plan, fire and rescue responders will respond to an event involving fire or hazardous material, mitigate the consequences, and bring the situation under control. The firefighters provided feedback that was positive concerning the information the controller provided to them.

\section{Discussion}

The Station 3 engine crew worked well with the controllers. The IC prevented the fighting of the diesel fire until power to the power pole had been isolated. Thereafter, the fire was quickly extinguished by $\mathrm{T}+40$, and the IC directed efficient handling of the victim.

\section{Issues}

- None.

\subsection{Reentry}

The ERO will demonstrate development and implementation of a reentry plan to include debriefing of the reentry team and proper recordkeeping in accordance with the facility procedures/plan.

\section{Discussion}

Reentry was considered, but it was not needed.

\section{Issues}

- None. 


\subsection{Recovery}

Given the facility procedures/plan, the ERO will demonstrate recovery planning for an emergency at the affected facility.

\section{Discussion}

At $\mathrm{T}+44$, the IC departed the scene to go to the ECC to develop a recovery action plan. He expressed the need to the EAM of having Power Management on scene when the recovery plan went into force to care for the downed power lines.

At $\mathrm{T}+74$, a recovery manager was appointed after approval by the ED.

Issues

- None.

\subsection{Drill/Exercise Conduct}

Write, conduct, and evaluate a drill/exercise that will emphasize facility-specific emergency events and response activities and minimize the use of generic, nonspecific simulations in accordance with the facility procedures/plan.

\section{Discussion}

An empty 1,000 gallon water tanker was provided from CFA to approximate the diesel tanker. The truck and a picture with photo-shopped images provided a realistic recreation of the incident scene scenario.

The process for the EAM and PAL to be able to communicate with area wardens during a take shelter action is limited to using the voice announcement system. There should be a process by which the EAM can receive and request information from the area warden coordinators when they are sheltered. No controller cue card was used to replicate this process for the PAL.

When the SMC planning communicator made a request of CFA planning to order a load of dirt to put around the spill area, he was told to call the SMC ECC logistics manager directly to make the request. The SMC controller was unaware of the procedural requirement and so some confusion ensued until a common procedural understanding was established between the CFA and SMC controllers. This was confusing for the players.

The drill was terminated at $\mathrm{T}+41$.

\section{Opportunities for Improvement}

- The SMC emergency planner should work closely with the PAL personnel to devise the process by which sheltered employees can be cared for during a take shelter event. This process should then be briefed to all area wardens and area warden coordinators. SMC LabWay No. SMC-Co 2014-1293 assigned.

- Emergency Management should review the requirement for a busy outlying ECC having to call the CFA logistics manager instead of just making the request via the CFA planning communicator. In the case of SMC with its ECC manning configuration, this may require the SMC planning communicator to leave the planning bridge to make that call, thus compromising the EAM's ability to request further support in a timely manner. Emergency Management will review/evaluate the procedure (or lack of) for requesting resources and provide interim guidance. Laboratory Protection LabWay

No. LP-CO-2014-0773 assigned. 


\section{CONCLUSIONS}

A successful evaluated exercise was conducted at SMC. The event involved SMC ERO members and control cells in the EOC and the CFA ECC.

The exercise was initiated by a controller briefing the shift supervisor of the basic incident scene characteristics. This resulted in the activation of the SMC, EOC, and CFA ERO teams. The applicable emergency action level was identified and an OE declared well within the required 15 minutes. Notifications to offsite agencies were completed within the required 30 minutes for an unclassified OE. PAs were reviewed throughout the event and adjusted as the event evolved.

INL FD Station 3 personnel responded, sized up the event, and deployed the necessary personnel and equipment to effectively mitigate the emergency. Security personnel established access control around the event area and maintained contact with the INL FD captain.

Effective communications were established using the appropriate communication protocols. Voice announcements were made at SMC to keep employees apprised of the drill character.

The transfer of the notification, categorization/classification, and PA functions was completed.

Emergency facilities and equipment were available and operated as designed.

A discussion occurred on the need for reentry, and it was determined not to conduct one. A recovery manager was appointed and recovery issues were discussed.

The SMC EAM demonstrated effective command and control skills. All other personnel functioning in leadership roles where command and control were essential functions demonstrated satisfactory performance.

Throughout the exercise, briefings were held within the ECC, and EAM provided timely updates on event conditions.

INL FD and medical personnel satisfactorily demonstrated proficiency in their response activities.

A successful briefing occurred on event termination that included controllers and evaluators, the SMC ERO team, and SMC operations observer personnel.

Overall, the exercise scenario was well written, conducted, and evaluated. Eight objectives were rated as satisfactory with four rated as satisfactory with improvement needed. The overall performance of SMC ERO members was satisfactory. 
This page intentionally left blank. 


\section{Appendix A}

\section{Scenario Narrative}


This page intentionally left blank. 


\section{Appendix A}

\section{Scenario Narrative}

\section{Background}

SMC is located on the INL Site and develops specific manufacturing capabilities as directed by the Department of Defense and manufactures armor for the U.S. Army. SMC is classified as a Department of Energy Hazard-Category-3 nuclear facility. SMC consists of fabrication and assembly, rolling operations, and support facilities and provides product and recyclable material transportation. Fabrication and assembly facilities contain production areas and space for offices, support functions, and service areas. TAN-679, TAN-679A, and TAN-681 operations include areas for process production; shipping, receiving, and storing material; a Radiological Control field office; a maintenance area; a boiler room; administrative offices; and change room facilities. SMC support facilities include a guard post (TAN-676), a cafeteria and an ECC (TAN-678), utilities, offices, a warehouse, and an office complex. Access to SMC is obtained through the TAN-676 guardhouse.

It was a normal working day at SMC.

\section{Drill Start}

A diesel fuel tanker was inside the facility preparing to back up to underground tank accesses. As the driver was positioning his truck, he had a heart attack. His foot pushed down on the accelerator, and he drove full speed into the main transformer light pole northeast of TAN-681. The force of the truck broke the pole in half, and it fell on to the top of the tanker truck and punctured its main tank. Diesel fuel poured out on to the ground and flowed toward TAN-681 and westward toward the facility fence.

The powered transformer and broken power lines ignited some diesel on the surface of the tanker. The driver (represented by a manikin) was slumped over the steering wheel.

The INL FD was dispatched to the scene. The SMC EAM directed the WCC to activate the SMC ECC and then made his way to the ECC. WCC established a conference call with the support director and the ED. The ED requested the activation of the CFA ECC, the EOC, and the JIC (simulated by control cells).

The SMC EAM arrived at the SMC ECC and categorized the event as a Non-radiological Release SMC-ALL-4.OE.1. An initial PA of sheltering for the facility was ordered by the EAM (simulated) and was upgraded to a full facility evacuation (simulated) later. Appropriate notification forms were completed and faxed to the WCC. Offsite notifications were simulated as being completed.

The INL FD arrived on scene and set up their command post in between TAN-679 and TAN-629. There was a small flame on the side of the tanker where the power lines had ignited some spilled diesel. Spilling diesel fuel spread toward TAN-681 and the facility's west fence. Because of the huge quantity of fuel available in the tanker and the possibility of an even more substantial fire and smoke, the EAM or IC chose to evacuate the entire facility. Evacuations were simulated, although planning and execution steps associated with the evacuations were required of the EAM. Even though not required initially for the sheltering action, accountability checks were performed by the PAL for the drill. 
The power was simulated as having been shut off to the power pole (causing simulated back-up generators to power up in the facility). The FD put the fire out and mitigated the fuel oil spill by using foam or dirt to contain the spill and stood by with hoses to put out a truck fire should the fire re-ignite. The IC directed the ambulance team to address the needs of the unconscious truck driver (manikin).

The EAM ensured that a consequence assessment form was faxed to the EOC concerning the burning and leaking diesel fuel.

The truck driver was revived and loaded into the ambulance for transport.

The IC and EAM decided to let the tanker drain down to the level of the hole because the hole could not be plugged. The EAM and the IC then planned recovery and appointed a recovery manager.

When all objectives were met, the drill was terminated, and an after action review was conducted. 